\title{
Covid-19 Pandemisi Sırasında Bir Pandemi Hastanesinde Jinekolojik Kanser Nedeniyle Opere Olan Hastalarda Kısa Dönem Cerrahi Sonuçlar: Tek Merkezli Retrospektif Olgu-Kontrol Çalışması
}

\section{Short Term Results of Gynecologic Cancer Patients Operated in a Pandemic Center Hospital During COVID-19 Pandemic: Single Center Retrospective Case-Control Study}

\author{
Murat ÖZ \\ Müfide İclal ALTINTAȘ ${ }^{2}$ \\ Burak ERSAK \\ Zeliha FIRAT CÜYLAN \\ Bülent ÖZDAL \\ Özlem MORALOĞLU TEKIN ${ }^{2}$
}

(1) orcid id:0000-0002-0629-5386

(1) orcid id:0000-0002-4318-8264

(1) orcid id:0000-0003-3301-062X

(1) orcid id:0000-0003-3382-8763

(1) orcid id:0000-0001-9829-688X

(1) orcid id:0000-0001-8167-3837

\footnotetext{
${ }^{1}$ Ankara Șehir Hastanesi Kadın Doğum Hastanesi, Jinekolojik Onkoloji Kliniği

2 T.C SB. Sağık Bilimleri Üniversitesi Ankara Șehir Hastanesi Kadın Hastanesi Ankara
}

\section{Öz}

Amaç: Tüm Dünya'da etkisini sürdüren yeni tip koronavirüs (COVID-19) pandemisi sürecinde sağık sistemi kaynakları pandemi ile mücadeleye aktarılırken rutin sağlık hizmeti sunumunda önemli değişikliklere gidilmiştir. Bu tek merkezli, retrospektif, olgu-kontrol çalışmasının amacı COVID-19 pandemisi sürecinde alınan tedbirlerin jinekolojik kanser cerrahisi uygulanan hastalarda kısa süreli cerrahi sonuçlara etkisini ortaya koymaktır.

Gereçler ve Yöntem: COVID-19 pandemi önlemlerinin alınmasından sonra opere edilen hastalar çalışma grubunu oluştururken, bu tarihten önce opere edilen hastalar kontrol grubunu oluşturdu. Çalışma grubundaki her bir hastaya karşılık yaş ( \pm 10$)$, tanı, evre ve yapılan operasyonun tipi yönünden eşleştirilen en az iki kontrol seçilerek klinikopatolojik değişkenler yönünden karşılaştıııldı.

Bulgular: Vaka ve kontrol grubu tanı, hastalık evresi ve yapılan ameliyatın şekli yönünden birebir eşleşirken her iki grup yaş, menopozal durum, ko-morbiditeleri ve aldıkları adjuvan tedavi yönünden benzer olarak bulundu. Vaka grubundaki hastaların ortalama hastanede yatış süresinin, kontrol grubundaki hastalara göre anlamlı olarak daha az olduğu görüldü (vaka grubunda ortalama $5,6( \pm 3,3)$ gün, kontrol grubunda ortalama $8,5( \pm 9,3)$ gün, $p=0,021)$. Vaka grubunda 5 hastaya $(\% 17,2)$ kontrol grubundaysa 18 hastaya $(\% 31,0)$ kan ürünü transfüzyonu ihtiyacı oldu, ancak iki grup arasındaki fark istatistiksel olarak anlamlı değildi $(p=0,16)$. Vaka grubundaki hastalarda kontrol grubuna göre daha az intraoperatif $(p=0,36)$ ve postoperatif $(p=0,34)$ komplikasyon izlenmesine karşın bu farklar istatistiksel olarak anlamllık arz etmiyordu.

Sonuç: COVID-19 pandemisi sonrasında opere edilen hastalarda daha az radikal cerrahi tercih edilmesi ile birlikte tutarlı bir şekilde hastanede yatış süresi, intraoperatif ve postoperatif komplikasyon oranlarının azaldığı ancak hastanede kalış süresi haricindeki değişkenlerin istatistiksel olarak anlamlı olmadığı bulunmuştur.

Anahtar Sözcükler: Koronavirüs, COVID-19, pandemi, jinekolojik kanser

\begin{abstract}
Aim: During the novel Coronavirus pandemic which is affecting the whole world, there have been major changes in routine healthcare system, while majority of resources were transferred to fight against the pandemic. The purpose of this single center retrospective case-control study is to evaluate the effect of certain precautions taken during the pandemic, on patients undergoing surgery for gynecologic cancer.
\end{abstract}

Materials and Method: The case group includes the patients which were operated after the pandemic measures, while the patients which were operated before were included in the control group. Patients in the case group were matched with two controls in regards of diagnosis, stage of disease, type of operation and age $( \pm 10)$.

Results: Case and control groups were same in regards of diagnosis, disease stage and type of operation, while age, menoposal status, co-morbidities and adjuvant treatment types were similar between both groups. The length of hospital stay was significantly shorter in the cases compared to controls $(5,6( \pm 3,3)$ days, vs $8,5( \pm 9,3)$ days, respectively, $p=0,021)$. Five patients $(17,2 \%)$ in the control group and 18 patients $(31,0 \%)$ in the control group required transfusion of blood products, however the difference was not statistically significant $(p=0,16)$. The cases had fewer intraoperative and postoperative complications, however this difference was not staatistically significant $(p=0,36$ and 0,34 , respectively)

Conclusion: We found that patients which were operated during the pandemic had slightly less radical procedures in regards of dissected lymph node counts. As well as the case group had shorter hospital stay, less intraoperative and postoperative complication rates, in which, only length of hospital stay was statistically significant.

Keywords: Coronavirus, COVID-19, pandemic, gynecologic cancer

\section{GiRiş}

Tüm dünyayı etkisi altına alan yeni tip koronavirüs (COVID-19) enfeksiyonunun 11 Mart 2020 tarihinde Dünya Sağlık Örgütü tarafından "Pandemi" olarak ilan edilmesinin (1) ardından Türkiye Cumhuriyeti Sağlık Bakanlığı sağık hizmetinin sunumu ile ilgili ivedilikle önlemler almıştır. 
Bu önlemler doğrultusunda sağlık hizmeti sunucuları kapasitelerinin önemli bölümünü COVID-19 pandemisi ile mücadeleye yönlendirmişlerdir. Bu süreçte özellikle kanser tanısı alan hastaların klinik yönetimleriyle ilgili karar aşamasında zorlu bir sürece girilmiştir.

Jinekolojik kanser tanısı alan hastaların pandemi sürecinde nasıl yönetileceğine dair Jinekolojik Onkoloji Cemiyeti (SGO), Avrupa Jinekolojik Onkoloji Cemiyeti (ESGO) gibi önde gelen uluslararası derneklerle birlikte Türk Jinekolojik Onkoloji Derneği (TRSGO) gibi ulusal derneklerin çeşitli önerileri mevcuttur(2, 3). Ancak bu öneriler kanıta dayalı değildir ve bu yaklaşımlarla elde edilecek onkolojik sonuçlar bilinmemektedir.

Jinekolojik kanserlerde erken tanı ve küratif cerrahiyi takiben hastaların prognozları çok iyi olabilmektedir. Bu nedenle kaynakların ve iş gücünün büyük bölümünün COVID-19 enfeksiyonu ile savaşa ayrılmasına rağmen jinekolojik kanser cerrahisinin diğer elektif cerrahiler gibi tamamen durdurulması söz konusu değildir. Ancak bu süreçte kaynaklar görece kısıtlı olduğundan operasyon hızlarının pandemi öncesindeki gibi olması da mümkün değildir. Bu bağlamda hangi hastaların pandemi döneminde opere edileceğinin, hangilerinin operasyonlarının ileri bir tarihe erteleneceği ve bu seçimin sağ kalıma etkisi bilinmemektedir. Buna ek olarak, cerrahi radikaliteyi asgariye indirmek gibi, hastaların morbidite ve hastanede kalış sürelerini azaltmaya yönelik tedbirlerin de kısa ve uzun vadeli sonuçları bilinmemektedir. Ayrıca COVID-19 tanısı alan ya da cerrahi öncesinde inkübasyon sürecinde olup postoperatif dönemde hastalık semptomlarını geliştiren hastaların prognozlarına dair geniş çaplı bilimsel veri henüz mevcut değildir. Çin' de yapılan ulusal tabanlı bir analizde kanserli olgular COVID-19 ile enfekte olduğunda, bu hastaların COVID-19' a bağlı ciddi olay geliştirme riskinin kanser tanısı olmayan hastalara göre 3,5 kat daha fazla olduğu bildirilmiştir (4). Liang ve arkadaşları, kanser tanısı olan kimselerin COVID-19' a yakalanma riskinin kanser tanısı olmayanlara göre daha yüksek olduğunu göstermiş ve kanser tanısı olan COVID-19 olgularındaki akıbetin kötü olduğunu bildirmiştir (4).

Hem jinekolojik onkoloji cerrahisi yapan kliniklerin esnek çalışma düzenine geçmesi, hem de cerrahi endikasyonların daraltılması nedeniyle jinekolojik kanser tanısı alan hastaların prognozlarının kötü etkilenmesi ve intraoperatif komplikasyonların artması şeklinde endişeler ortaya çıkmıştır. Jinekolojik kanser tanısı alanlarda küratif cerrahinin ertelenmesinin hastalar açısından kötü sonuçlar doğurabileceği bildirilmiştir (5). Çalışmamızın yürütüldüğü Ankara Şehir Hastanesi Jinekolojik Onkoloji Kliniği'nde Sağlık Bakanlığı'nın önerileri doğrultusunda esnek mesai düzenine geçilerek gün içerisinde klinikte aktif çalışan hekim sayısı yarı oranda azaltılarak yukarıda değinilen dernek önerileri doğrultusunda jinekolojik kanser hastalarının yönetiminde birtakım değişikliklere gidilmiştir.

Jinekolojik kanser cerrahisi, Amerikan Cerrahlar Cemiyeti tarafından "yarı-acil cerrahi” olarak kabul edilmektedir (6). Jinekolojik Onkoloji Cemiyeti ise jinekolojik kanser cerrahilerini endikasyonlarına göre acil, yarı-acil ve acil olmayan durumlar olmak üzere 3 gruba ayırmıştır (3). Bu bağlamda kurumumuzda vulvar ve servikal preinvaziv lezyonlara yönelik tanı ve tedavi prosedürleri 3 ay süresince durdurulmuş, endometriyal preinvaziv lezyonlarda (EIN, atipili endometriyal hiperplazi, vs) intrauterin ya da oral progestin tedavisi birinci öncelik olarak hastalara sunulmuş, endometrium kanseri tanısı olan hastalar intraoperatif frozen sonucuna göre yönetilmiş, malignite riski düşük adneksiyal kitleler altışar haftalık intervallerle takibe alınırken, yüksek riskli adneksiyal kitlelerde ise operasyon kararı verilmiştir. Klinik olarak ileri evre epitelyal over kanseri düşünülen hastalarda birinci seçenek olarak doku biyopsisi ile tanının kesinleştirilmesinin ardından neo-adjuvan kemoterapiye yönlendirilirken, daha önce tanı alıp da 3 siklus neo-adjuvan kemoterapisini tamamlayan hastalar klinik ve görüntüleme olarak tekrar değerlendirilip komplet ya da komplete yakın yanıt gözlenirse operasyon yönünde, sub-optimal yanıt gözlenirse neo-adjuvan kemoterapiyi 6 siklusa tamamlama yönünde karar alınmışıı. İnvaziv serviks kanserinin cerrahi yönetim endikasyonları ise pandemi öncesi döneme göre herhangi bir değişiklik göstermemiştir.

Bu süreçte minimal invaziv cerrahinin kullanımına yönelik özellikle pnömoperitoneum gazının operasyon odasına dağılmasının yaratacağı teorik riskler nedeniyle birtakım çekinceler mevcuttur. Ayrıca rejyonel anestezi kullanımın minimal invaziv cerrahi için konforlu olmaması ve sıklıkla entübasyon gerekmesi nedeniyle, anestezi klinikleri de bu konuda çekimser davranmaktadır (7).

$\mathrm{Bu}$ tek merkezli, retrospektif, olgu-kontrol çalışmasının amacı COVID-19 pandemisi sürecinde alınan tedbirlerin jinekolojik kanser cerrahisi uygulanan hastalarda kısa süreli cerrahi sonuçlara etkisini ortaya koymaktır.

\section{GEREÇ VE YÖNTEMLER}

27.04.2020/004 tarih sayı numaralı yerel akademik kurul ve 30.04.2020 ta- rihli T.C. Sağlık Bakanlığı Bilimsel Araştırma Platformu tarafından çalışma başvurusunun onaylanmasının ardından Ankara Şehir Hastanesi Jinekolojik Onkoloji Kliniği'nde jinekolojik kanser tanısı alıp opere edilen hastaların verileri retrospektif olarak incelendi. Bu bağlamda COVID-19 pandemi önlemlerinin alınmasından sonra opere edilen hastalar çalışma grubunu oluştururken, bu tarihten önce opere edilen hastalar kontrol grubunu oluşturdu. Çalışma grubundaki her bir hastaya karşılık yaş $( \pm 10)$, tanı, evre ve yapılan operasyonun tipi yönünden eşleştirilen hastalar arasından bağımsız rastgele örneklem metodu ile en az iki kontrol seçilerek aşağıda belirtilen değişkenler yönünden karşılaştırıldı. Ayrıca pandemi önlemlerinin ardından opere edilen hastaların cerrahi sonrası 30 günlük takiplerinde COVID-19 enfeksiyonu saptanma oranları ve bu hastaların diğer hastalara kıyasla mortalite ve morbidite yönünden farkları araştıııldı.

\section{Dahil edilme kriterleri:}
- 18 yaş üzerinde;
- COVID-19 pandemi önlemleri öncesinde jinekolojik kanser tanısı ile opere edilen hastalar

- $\quad$ COVID-19 pandemi önlemleri sonrasında jinekolojik kanser tanıSı ile opere edilen hastalar

- $\quad$ COVID-19 pandemi önlemleri sonrasında jinekolojik kanser tanıSı ile opere edilen, ve operasyondan sonra 30 gün içerisinde COVID-19 tanıs। alan hastalar

Analiz edilen değişkenler:

Yaş, tanı, hastalık evresi, histolojik grade, yapılan operasyon, tanı tarihi, operasyon tarihi, , ASA skoru, mevcut ek hastalık (sigara, KOAH, konjestif kalp yetmezliği, koroner arter hastalığı, DVT/PTE öyküsü, hipertansiyon, diyabet, inme, diğer), cerrahinin elektif ya da acil şartlarda yapıldığı, anestezi tipi, operasyon tipi (laparotomi, minimal invaziv, minimal invazivden laparotomiye dönüş), post-operatif 30 gün içerinde COVID-19 tanısı (laboratuvar, toraks BT) ve ne zaman aldığı, adjuvan tedavi şekli, preoperatif rutin laboratuvar tetkikleri

Komplikasyonlar (intraoperatif komplikasyonlar kan ve kan ürünleri transfüzyonu ihtiyacı, toplam hastanede kalış süresi, yoğun bakım intiyacı, yoğun bakımda kalış süresi, postoperatif enfeksiyon, relaparotomi, vb), ölüm, ölüm tarihi.

\section{İstatistik analiz:}

İstatistik analiz için SPSS 24.0 (IBM Corp, Armonk, NY, USA) programı kullanıldı. Devamlı değişkenler için sonuçlar ortalama ve ortanca şeklinde ifade edildi. Normal dağııma uymayan sürekli değişkenlerin karşılaştııımasında non-parametrik testler (Mann-Whitney U), normal dağlıma uyan sürekli değişkenlerin karşılaştırılmasında parametrik testler (Student's t-test), nominal ve ikili değişkenlerin karşılaştırmasında ki-kare testi kullanıldı. $p<0,05$ istatistiksel olarak anlamlı kabul edildi.

\section{BULGULAR}

Çalışmaya dahil olma kriterlerine uygun olarak kliniğimizde pandemi önlemlerinin alınmasından sonra jinekolojik kanser tanısı ile opere olan 32 hasta vaka grubu için seçildikten sonra 3 vakanın kontrolü bulunamadı. Bu nedenle vaka grubu 29 olgudan oluştu. Eşleştirme kriterlerine uygun olarak, her bir vakaya karşılık ikişer kontrol hastası olmak üzere toplam 87 hastanın verileri incelendi (Şekil 1).

Sekil 1. Calıșmanın akıs seması

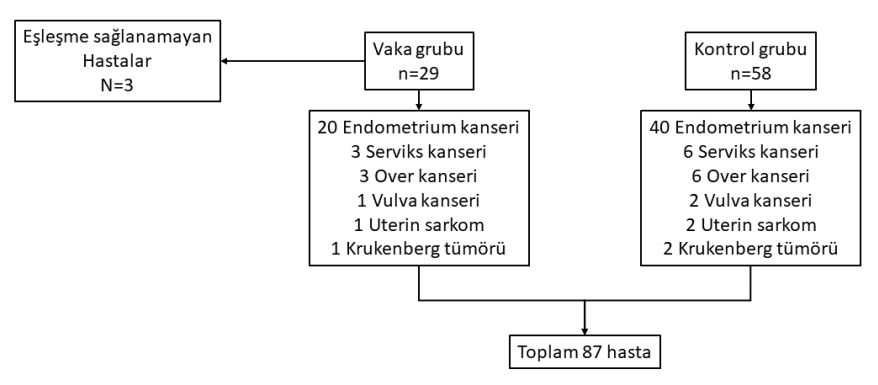


Hastaların demografik ve klinikopatolojik bilgileri Tablo 1' de gösterildiği gibidir. Vaka ve kontrol gruplarında hastaların ortalama yaşları sırası ile 55,0 $( \pm 12,2)$ ve $58,0( \pm 11,3)$ olarak bulunurken iki grup arasında anlamlı bir fark saptanmadı $(p=0,26)$. Vaka grubundaki hastaların 7 'si $(\% 24,1)$ premenopozal dönemdeyken, kontrol grubundaki hastaların 9 tanesi $(\% 15,5)$ premenopozal dönemdeydi ve menopozal durum açısından her iki grup arasında anlamlı fark saptanmadı. Vaka grubunda 20 hasta endometrium kanseri $(\% 69,9), 3$ hasta serviks kanseri $(\% 10,3), 3$ hasta over kanseri $(\% 10,3) 1$ hasta uterin sarkom $(\% 3,4)$ ve 1 krukenberg tümörü $(\% 3,4)$ tanıları ile opere edildi. Hastaların FIGO evrelerinin dağılımına baktığımızda, vaka grubunda 19 hasta evre I $(\% 65,5), 1$ hasta evre II $(\% 3,4), 3$ hasta evre III (\%24,1) ve 1 hasta da evre IV $(\% 3,4)$ olarak saptandı. Hastaların tamamı elektif endikasyonlar ile küratif amaçlı opere edilmişlerdi, acil ya da palyatif amaçıı opere edilen hasta yoktu. Hem vaka hem de kontrol grubundaki hastaların tamamına operasyon sırasında genel anestezi uygulandı. Vaka grubundaki 29 hastanın 17'sinde $(\% 58,6)$, kontrol grubunda ise 58 hastanın 35 'inde $(\% 60,3)$ komorbidite mevcuttu $(p=0,87)$. Hastaların komorbiditelerinin ayrıntıları Tablo 1'de gösterilmiştir. Preoperatif dönemde ya da postoperatif takiplerde hiçbir hastaya COVID-19 enfeksiyonu tanısı konmadı.

Vaka grubunda 11 hasta $(\% 37,9)$ adjuvan tedavi alırken, kontrol grubunda 19 hasta $(\% 32,8)$ adjuvan tedavi almıştır ve iki grup arasında adjuvan tedavi açısından anlamlı fark yoktur $(p=0,63)$. Adjuvan tedavi şekilleri Tablo 1 'de ayrıntılı olarak sunulmuştur.

Çalışmaya dahil edilen tüm hastalara laparotomi yapıımıştır, minimal invaziv cerrahi yapılan hasta yoktur. Vaka grubunda toplam 22 hastaya, kontrol grubunda ise 44 hastaya retroperitoneal lenf nodu diseksiyonu yapılmışıı. Çıkarılan median lenf nodu sayısı vaka grubunda 36 (5-101), kontrol grubunda ise 44,5 (10-112) olarak bulunmuş ve iki grup arasında istatistiksel olarak anlamlı fark bulunmamıştır $(p=0,23)$. Vaka ve kontrol gruplarında çıkarılan lenf nodu sayıları Tablo 1'de ayrıntılı olarak gösterilmektedir.

Tablo 1. Hastaların klinikopatolojik özellikleri

\begin{tabular}{|c|c|c|c|}
\hline & $\begin{array}{l}\text { Vaka Grubu } \\
n=29\end{array}$ & $\begin{array}{l}\text { Kontrol Grubu } \\
\mathrm{n}=58\end{array}$ & $\mathrm{p}$ değeri \\
\hline Histolojik Tanı (n,\%) & & & 1 \\
\hline Endometrium Kanseri & $20(\% 69,0)$ & $40(\% 69,0)$ & \\
\hline Serviks Kanseri & $3(\% 10,3)$ & $6(\% 10,3)$ & \\
\hline Over Kanseri & $3(\% 10,3)$ & $6(\% 10,3)$ & \\
\hline Vulva Kanseri & $1(\% 3,4)$ & $2(\% 3,4)$ & \\
\hline Uterin Sarkom & $1(\% 3,4)$ & $2(\% 3,4)$ & \\
\hline Krukenberg Tümörü & $1(\% 3,4)$ & $2(\% 3,4)$ & \\
\hline FIGO Evre & & & 1 \\
\hline I & $19(\% 65,5)$ & $38(\% 65,5)$ & \\
\hline II & $1(\% 3,4)$ & $2(\% 3,4)$ & \\
\hline III & $7(\% 24,1)$ & $14(\% 24,1)$ & \\
\hline IV & $1(\% 3,4)$ & $2(\% 3,4)$ & \\
\hline Yaş (Ortalama, \pm SD) & $55,0 \pm 12,2$ & $58,0 \pm 11,3$ & 0,25 \\
\hline Menopozal durum & & & 0,32 \\
\hline Premenopozal (n,\%) & $7(\% 24,1)$ & $9(\% 15,5)$ & \\
\hline Postmenopozal (n,\%) & $22(\% 75,9)$ & $49(\% 84,5)$ & \\
\hline Komorbidite varlığ $(\mathrm{n}, \%)$ & $17(\% 58,6)$ & $35(\% 60,3)$ & 0,87 \\
\hline Sigara kullanımı & 0 & $2(\% 3,4)$ & \\
\hline $\mathrm{KOAH}$, pulmoner hastalık & 0 & 0 & \\
\hline KKY & 0 & 0 & \\
\hline $\mathrm{KAH}$ & $3(\% 10,3)$ & $1(\% 1,7)$ & \\
\hline DVT/PTE öyküsü & 0 & 0 & \\
\hline HT & $12(\% 41,4)$ & $24(\% 41,4)$ & \\
\hline $\mathrm{DM}$ & $3(\% 10,3)$ & $12(\% 20,7)$ & \\
\hline SVO öyküsü & 0 & 0 & \\
\hline Kronik renal hastalık & 0 & 0 & \\
\hline Kronik karaciğer hastalığ & 0 & 0 & \\
\hline Diğer & $2(\% 6,9)$ & $5(\% 8,6)$ & \\
\hline
\end{tabular}

\begin{tabular}{|l|l|l|l|}
\hline Adjuvan tedavi & $18(\% 62,1)$ & $39(67,2)$ & \\
Almadı & $11(\% 37,9)$ & $19(32,8)$ & \\
Aldı & $5(\% 17,2)$ & $12(\% 20,7)$ & \\
Kemoterapi & $5(\% 17,2)$ & $4(\% 6,9)$ & \\
Radyoterapi & $1(\% 3,4)$ & $3(\% 5,2)$ & \\
Kemoradyoterapi & & & 1 \\
\hline Retroperitoneal LND & $7(\% 24,1)$ & $14(\% 24,1)$ & \\
Yapılmadı & $22(\% 75,9)$ & $44(\% 75,9)$ & \\
Yapıldı & $36(5-131)$ & $47(10-112)$ & 0,098 \\
\hline Ç1karılan toplam LND sayısı (ortanca, min-max) & &
\end{tabular}

FIGO, International Federation of Gynecology and Obstetrics; KOAH, kronik obstuktif akciğer hastalığı; KKY, konjestif kalp yetmezliği; KAH, koroner arter hastalığı; DVT, derin ven trombozu; PTE, pulmoner tromboemboli; HT, hipertansiyon; DM, diyabetes mellitus; SVO, serebro vasküler olay; LND, lenf nodu diseksiyonu

Vaka grubundaki hastaların ortalama hastanede yatış süresinin, kontrol grubundaki hastalara göre anlamlı olarak daha az olduğu görüldü (vaka grubunda ortalama 5,6 $( \pm 3,3)$ gün, kontrol grubunda ortalama 8,5 $( \pm 9,3)$ gün, $p=0,021)$. Vaka ve kontrol grupları arasında yoğun bakım ihtiyacı ve yoğun bakımda kalınan gün sayısı yönünden anlamlı fark bulunmadı. Vaka grubunda 5 hastaya $(\% 17,2)$ kontrol grubundaysa 18 hastaya $(\% 31,0)$ kan ürünü transfüzyonu intiyacı oldu, ancak iki grup arasındaki fark istatistiksel olarak anlamlı değildi $(p=0,16)$. Vaka grubundaki hastalarda kontrol grubuna göre daha az intraoperatif $(p=0,36)$ ve postoperatif $(p=0,34)$ komplikasyon izlenmesine karşın bu farklar istatistiksel olarak anlamlılık arz etmiyordu. Hastaların postoperatif sonuçları Tablo 2'de detaylı olarak sunulmuştur.

Tablo 2. Hastaların Postoperatif Sonuçları

\begin{tabular}{|c|c|c|c|}
\hline & $\begin{array}{l}\text { Vaka Grubu } \\
n=29\end{array}$ & $\begin{array}{l}\text { Kontrol Grubu } \\
n=58\end{array}$ & $p$ değeri \\
\hline Hastanede toplam yatış günü, (ortanca, min-max) & $4,0(2-15)$ & $6,5(2-55)$ & 0,021 \\
\hline Yoğun bakım ihtiyacı & & & 0,74 \\
\hline Olmadi (n, \%) & $2(\% 6,9)$ & $3(\% 5,2)$ & \\
\hline Oldu (n, \%) & $27(\% 93,1)$ & $55(\% 94,8)$ & \\
\hline Yoğun bakımda yatış günü (ortanca, min-max) & $1(0-2)$ & $1(0-40)$ & 0,95 \\
\hline Kan ürünü transfüzyon ihtiyac1 & & & 0,34 \\
\hline Olmadı (n, \%) & $24(\% 82,8)$ & $40(\% 69,0)$ & \\
\hline Oldu (n, \%) & $5(\% 17,2)$ & $18(\% 31,0)$ & \\
\hline İntraoperatif komplikasyon & & & 0,36 \\
\hline Olmadi (n, \%) & $28(\% 96,6)$ & $53(\% 91,4)$ & \\
\hline Oldu (n, \%) & $1(\% 3,4)$ & $5(\% 8,6)$ & \\
\hline Üriner sistem yaralanması & $1(\% 3,4)$ & 0 & \\
\hline Vasküler yaralanma & 0 & $2(\% 3,4)$ & \\
\hline Gastro intestinal sistem yaralanmas1 & 0 & $1(\% 1,7)$ & \\
\hline Postoperatif komplikasyon & & & 0,34 \\
\hline Olmadı (n, \%) & $27(\% 93,1)$ & $50(\% 86,2)$ & \\
\hline Oldu (n, \%) & $2(\% 6,9)$ & $8(\% 13,8)$ & \\
\hline Kesi yeri enfeksiyonu & $2(\% 6,9)$ & $3(\% 5,1)$ & \\
\hline İntra abdominal enfeksiyon & 0 & $2(\% 3,4)$ & \\
\hline Şilöz asit & 0 & $4(\% 6,9)$ & \\
\hline
\end{tabular}

\section{TARTIŞMA}

İcerisinde bulunduğumuz yeni tip koronavirüs (COVID-19) pandemisi sürecinde jinekolog onkologlar olarak bizlerin esas yükümlülüğü, jinekolojik kanser hastalarının en üst düzeyde ve eksiksiz hizmet almalarının yanı sıra, kendi ekibimizdeki sağık çalışanlarının da güvenliklerinin sağlanmasıdır. Sağlık sisteminin kapasitesinin önemli bölümünün COVID-19 enfeksiyonu ile savaşa yönlendirildiği bu günlerde jinekolojik kanser hastaları için kısıtlı olan kaynakların akılcı kullanımı ile ilgili birtakım düzenlemelere gidilmesi gerekmiştir. Jinekolojik kanser hastalarının yönetiminde önerilen yönetim değişikliklerinin amacı mümkün olan asgari sayıdaki sağlık çalışanı ile hizmet vererek, cerra- 
hi endikasyonları ve cerrahi radikaliteyi azaltarak hastaların hastanede yatış sürelerini minimumda tutmaktır, bunu yaparken de onkolojik sonuçların kötüleşmemesi hedeflenmelidir (8). Hastaların yönetiminde yapılması önerilen değişikliklerin önemli bir bölümünün uzun dönem sonuçları bilinmemektedir. Çalışmamızın bu konuda literatüre katkı sağlayacağını düşünmekteyiz.

Çin'den gelen verilere göre pandeminin çıkış kaynağı olan Wuhan eyaletinde hastanede jinekolojik cerrahi endikasyonu ile yatan hastalarda COVID-19 enfeksiyonu görülme oranı \%1,59 olarak bildirilmektedir (9). Ancak bizim çalışmamıza dahil edilen hastaların hiçbirisinde preoperatif ve postoperatif dönemde COVID-19 enfeksiyonu tanısı konmamıştır. Benzer şekilde Aminian ve ark. İran'da elektif cerrahi sırasında inkübasyon periyodunda olup da postoperatif dönemde kinik enfeksiyon bulguları geliştiren 3 hastanın ikisinin kaybedildiğini, cerrahi geçirmiş hastalarda ve özellikle malignitesi olanlarda COVID-19 enfeksiyonunun daha ölümcül olabileceğini savunmaktadır (10). Kanser hastalarının COVID-19 enfeksiyonuna bağlı gelişen ciddi solunum yolu ve pulmoner komplikasyonların normal popülasyona kıyasla 4-8 kat daha fazla görüldüğü bilinmektedir (11). Bunun nedeni hem kanserin hem de majör cerrahinin immün sistem üzerine baskılayıcı etkisi sonucunda $\mathrm{CO}$ VID-19 enfeksiyonunun bu grup hastalarda çok daha hızlı ilerlemesi olarak belirtilmektedir (12).

Mevcut çalışmada, vaka grubundaki hastalarda ortalama 36 lenf nodu diseke edilirken bu sayı kontrol grubunda 47 olarak bulundu. Pandemi önlemlerinin alınmasından sonra yapılan operasyonlarda ortalama olarak daha az lenf nodu çıkarılması sonucunda beklenen sonuç intraoperatif ve postoperatif komplikasyonların belli oranda düşmesidir. Çalışmamızda da buna paralel olarak pandemi önlemlerinden sonra opere edilen hastalarda hastanede yatış süresinin anlamlı olarak azaldığı görülmektedir. Kontrol grubundaki hastaların \%31'i kan ürünleri transfüzyonuna intiyaç duyarken vaka grubundaki hastaların yalnızca \%17,2'sinde transfüzyon intiyacı olmuştur. Yine benzer şekilde intrapoeratif komplikasyon oranları kontrol ve vaka gruplarında sırası ile $\% 8,6$ ve $\% 3,4$ oranında izlenirken postoperatif komplikasyonlar ise kontrol grubunda 2 kat daha fazla izlenmiş (sırası ile $\% 13,8$ ve \%6,9) ancak bu farklar istatistiksel olarak anlamlı saptanmamıştır.

Bu çalışma, bilindiği kadarıyla, COVID-19 pandemi önlemlerinin jinekolojik kanser cerrahisi uygulanan hastaların intraoperatif ve erken postoperatif sonuçları üzerine etkisini gösteren ilk çalışmadır. Çalışmamızın güçlü yönü, vaka ve kontrol grubundaki hastalar arasında hastalık tanısı, evresi ve yapılan cerrahinin şekli açısından tam eşleşme yapılarak, diğer değişkenlerin gruplar arasındaki dağılımı hakkında daha doğru yorumlar yapılabilmesine olanak sağlanmasıdır. Bunun yanında her iki grupta hastalar yaş, komorbidite ve adjuvan tedavi bakımından benzerdi. Yine muhtemel biası en aza indirmek amacı ile vaka grubundaki tüm hastalara laparotomi ile açık cerrahi yapıldığından, kontrol grubundaki hastalar da buna uygun olarak açık cerrahi yapılan hastalar arasından seçilmiştir. Pandemi döneminde opere edilen hasta sayısının az olması ile, hastaların postoperatif uzun dönem morbidite ve sağ kalım sonuçlarının değerlendirilememiş olması çalışmamızın limitasyonları arasında sayılabilir.

Çalışmamızda sonuç olarak, COVID-19 pandemisi sonrasında opere edilen hastalarda daha az radikal cerrahi tercih edilmesi ile birlikte tutarlı bir şekilde hastanede yatı̧ süresi, intraoperatif ve postoperatif komplikasyon oranlarının azaldığı ancak hastanede kalış süresi haricindeki değişkenlerin istatistiksel olarak anlamlı olmadığı bulunmuştur. Bunun en muhtemel nedeni mevcut çalışmadaki vaka sayısının yeterli olmaması olarak öngörülebilir. Bu nedenle başka merkezlerin katılımı ile daha büyük ölçekte yapılacak bir vaka-kontrol çalışmasının bu sorulara daha net bir şekilde cevap vereceğini düşünmekteyiz. COVID-19 pandemisi hızını yitirdikten sonra bile yeni tip koronavirüs hayatımızda yer etmeye devam edecek ve belki de bu süreçte alınan önlemlerin bir bölümü kalıcı hale gelerek hastaların gelecekteki yönetim şekillerini belirleyecektir.

\section{REFERANSLAR}

1.WHO Timeline - COVID-19 2020 [Available from: https://www.who.int/ news-room/detail/27-04-2020-who-timeline---covid-19.

2.COVID 19: Elective Case Triage Guidelines for Surgical Care, College of American Surgeons 2020 [Available from: https://www.facs.org/covid-19/clinical-guidance/elective-case.

3.Surgical Considerations for Gynecologic Oncologists During the COVID-19 Pandemic, Society of Gynecologic Oncology 2020 [Available from: https:// www.sgo.org/wp-content/uploads/2020/03/Surgical_Considerations_Communique.v14.pdf.

4.Liang W, Guan W, Chen R, Wang W, Li J, Xu K, et al. Cancer patients in SARS-CoV-2 infection: a nationwide analysis in China. Lancet Oncol.
2020;21(3):335-7.

5.Cortiula F, Pettke A, Bartoletti M, Puglisi F, Helleday T. Managing COVID-19 in the oncology clinic and avoiding the distraction effect. Ann Oncol. 2020;31(5):553-5.

6.COVID 19: Elective Case Triage Guidelines for Surgical Care (Gynecology), College of American Surgeons 2020 [Available from: https://www.facs.org/-/ media/files/covid19/guidance_for_triage_of_nonemergent_surgical_procedures_gynecology.ashx.

7.Cohen SL, Liu G, Abrao M, Smart N, Heniford T. Perspectives on Surgery in the Time of COVID-19: Safety First. J Minim Invasive Gynecol. 2020;27(4):792-3.

8.Ramirez PT, Chiva L, Eriksson AGZ, Frumovitz M, Fagotti A, Gonzalez Martin A, et al. COVID-19 Global Pandemic: Options for Management of Gynecologic Cancers. Int J Gynecol Cancer. 2020.

9.Yang S, Zhang Y, Cai J, Wang Z. Clinical Characteristics of COVID-19 After Gynecologic Oncology Surgery in Three Women: A Retrospective Review of Medical Records. Oncologist. 2020.

10.Aminian A, Safari S, Razeghian-Jahromi A, Ghorbani M, Delaney CP. COVID-19 Outbreak and Surgical Practice: Unexpected Fatality in Perioperative Period. Ann Surg. 2020.

11.Akladios C, Azais H, Ballester M, Bendifallah S, Bolze PA, Bourdel N, et al. Recommendations for the surgical management of gynecological cancers during the COVID-19 pandemic - FRANCOGYN group for the CNGOF. J Gynecol Obstet Hum Reprod. 2020:101729.

12.Besnier E, Tuech JJ, Schwarz L. We Asked the Experts: Covid-19 Outbreak: Is There Still a Place for Scheduled Surgery? "Reflection from Pathophysiological Data". World J Surg. 2020;44(6):1695-8. 